\title{
Development of energy harvesting from burning process for community need via IoT based system
}

\author{
Rahaini Mohd Said, Nagen Krishnan, Amardeep Singh Dhillon, Nor Hafizah Hussin, \\ Shamsul Fakhar Abd Gani
}

Faculty of Electrical and Electronic Engineering Technology, Universiti Teknikal Malaysia Melaka, Malaysia

\begin{tabular}{|c|c|}
\hline Article Info & ABSTRACT \\
\hline Article history: & In this paper, a proposal was made to recreate an energy harvesting technique \\
\hline Received Sep 8, 2019 & $\begin{array}{l}\text { using biomass energy such as twigs, leaves, wood, paper, and charcoal emitted } \\
\text { by burning the said materials and harvest the energy from the released heat. }\end{array}$ \\
\hline Revised Nov 9, 2019 & The harvested energy is then converted into a voltage that can be used to \\
\hline Accepted Nov 23, 2019 & \\
\hline \multirow{7}{*}{$\begin{array}{l}\text { Keywords: } \\
\text { Biomass energy } \\
\text { Electricity } \\
\text { Energy harvesting } \\
\text { IoT } \\
\text { Power }\end{array}$} & The system can also be used to charge electronic devices during outdoor \\
\hline & activities in remote areas where electricity is inaccessible such as camping or \\
\hline & also be extremely beneficial in third world countries. The cost of the module \\
\hline & used is also much cheaper than other existing harvesting methods such as solar \\
\hline & panels or water turbines. Based on test data collected using IoT platform, \\
\hline & $\begin{array}{l}\text { charcoal was determined as the best material in terms of output power } \\
\text { generated. }\end{array}$ \\
\hline & $\begin{array}{r}\text { Copyright } \odot 2020 \text { Institute of Advanced Engineering and Science. } \\
\text { All rights reserved. }\end{array}$ \\
\hline
\end{tabular}

Corresponding Author:

Nagen Krishnan,

Faculty of Electrical and Electronic Engineering Technology,

Universiti Teknikal Malaysia Melaka,

Hang Tuah Jaya, 76100 Durian Tunggal, Melaka, Malaysia.

Email: nagen_9292@yahoo.com

\section{INTRODUCTION}

Energy availability is one of the most crucial factors for the advancement of a nation's economy and social development. Malaysia is gifted with an abundance of renewable energy sources such as hydro, wind, solar, geothermal and tidal wave but most of these renewable energy resources are currently not fully utilized $[1,2]$. Greater utilization of these assets will require focused efforts on different perspectives as well as exhaustive tests. Solar is one of the most used techniques that can be seen implemented in many places in Malaysia.

Solar energy is one of the most popular types of renewable energy in Malaysia because of its easy implementation. Most companies and even private household in Malaysia used solar energy as their alternative source other than the typical electricity supply [3]. One thing to consider when using solar panel is it is usually expensive when it comes to maintenance, and the size of the tile is rather large and consumes a lot of space for the implementation $[4,5]$. Thermoelectric generator (TEG) module is another alternative way to harvest the heat energy and convert it to electricity as what solar panel did but with a low cost [6, 7]. In this paper, a product prototype has been invented by using the TEG module, to convert the heat energy into electrical energy and channel it into AC and DC. TEG is used in this project mainly due to the cheap cost and easy maintenance. TEG module is small and doesn't consume much space if compared to a solar tile [8].

Recently many researchers are interested with energy harvesting, which is the process of extraction energy from the external surrounding of an environment. Olsten [9] claimed to answer for little off grid-scale 
control by misusing the temperature inclination that exists in the normal environment. The results shown in the paper shows that the proposed device can function both in the wintertime as well as summertime. In 2017, Sweta Kumari proposed combining low voltage internal start-up circuit and DC-DC boost converter for low voltage TEG. Reported results showed that the maximum power output voltage of $40 \mu \mathrm{W}$ has been extracted across the inductor base boost converter [10]. Additionally, Nazri [11] introduced Portable Power Supply (PosHEAT) as renewable energy which produces electrical energy from waste heat. The paper highlights the Seebeck theory and electrical system design for storage of the energy. According to the results, the selected Seebeck unit can produce enough energy to charge any type of mobile phones.

Other previous studies present proof of a feasible TEG-based gadget, but the devices perform differently under different climate conditions and distinctive outline parameters. For the development of this system, the electrical energy received from the TEG will be stored in a battery, and it will continuously recharge itself as long as the burning process is happening. A real-time monitoring system integrated with IoT is also implemented for the purpose of collecting data such as emissivity of the material, temperature, voltage that produce by TEG based on the material for a span of time and smoke parameter that has been filtered. This data is used for analysis and improves this system better as value-added innovation for future commercialization. As of late, cell phones have turned out to be very popular and is the most used gadget. In any case, a cell phone is a gadget that is power-hungry. If the cell phone battery is empty after use, the cell phone couldn't be used again until the battery is recharged.

\section{METHODOLOGY}

TEG module is used as the primary element to convert the heat energy into electrical energy [12] and the output from the TEG will be stored into a battery and it will keep recharging while the burning process is happening. Figure 1 shows the block diagram of this system. Biomass source such as wood, leaves, twigs, paper, and charcoal were used for testing the product and the resulting output is analyzed in terms of the material heat emissivity to understand the power gain produced according to each material [13]. Sensors such as temperature, smoke, weight, and current are installed and connected to the Arduino Uno for extracting the data and imported to the cloud server.

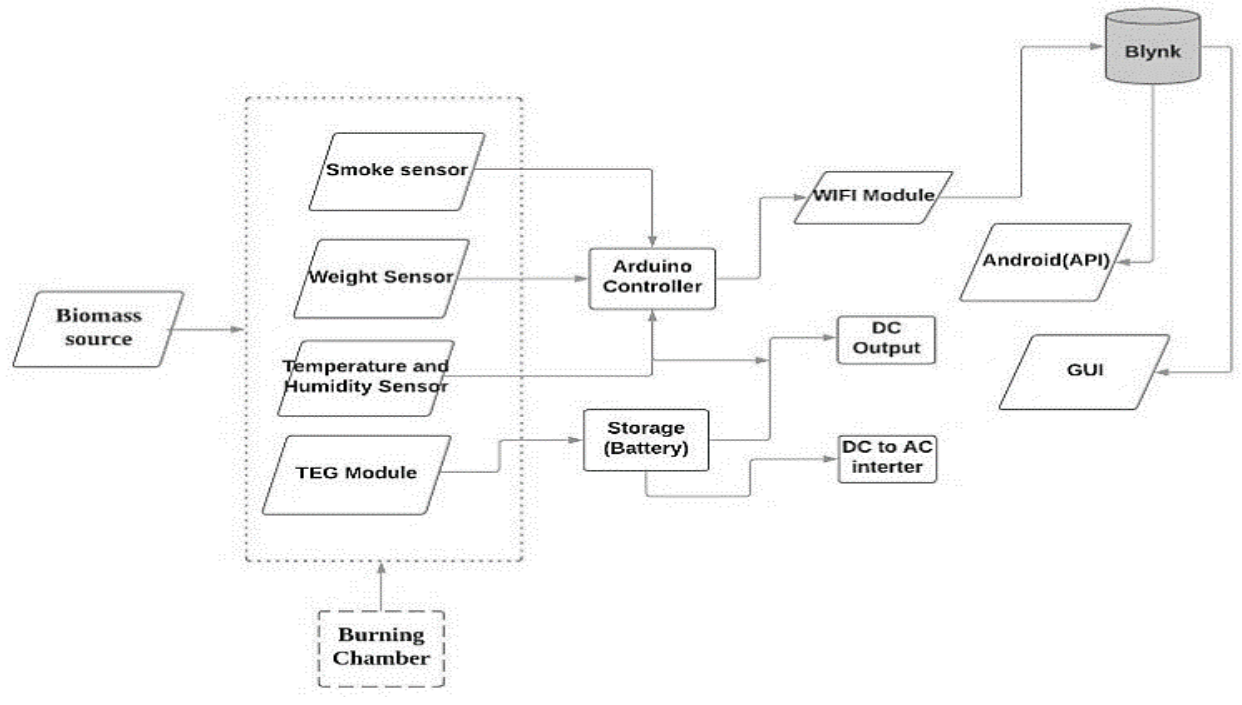

Figure 1. Block diagram of the project

Blynk server was used as the cloud services in this project, and the logged data can be retrieved in the form of an API that is connected to Android smartphones and GUI based system on a PC. The monitoring system is activated via the ESP8266 by using hotspot from the phone and the data is continuously sent to the cloud. The stored power source from the battery which is in DC supply will also be inverted to AC supply so that any electrical appliance can be connected directly to the power socket $[14,15]$.

Furthermore, 5 different sensors are used in this hardware in order to capture 5 different variables of data. The sensors are weight, voltage, current, temperature and smoke. The temperature sensor used here is thermocouple which can measure temperature ranging from 0 to $1024 \mathrm{deg} \mathrm{C}$ (32 deg F to $1875 \mathrm{~F}$ ) [16-18]. Next, the weight sensor HX711 load cell amplifier can measure up to 5kg. MQ-7 module Carbon monoxide gas sensor was used to detect the smoke and the detectable concentration is10-1000ppmCO. 5A Range Current 
Sensor Module ACS712 was used to read the current reading and voltage detection module voltage sensor for Arduino voltage with a detection range of DC $0.02445 \mathrm{~V}-25 \mathrm{~V}$ [19] was used to record voltage reading.

\subsection{Hardware Implementation}

There are five important elements in order to execute this project successfully, which are; TEG module, Arduino, sensors, ESP8266 Wi-Fi module, and cloud or server platform. As shown in Figure 2(a) the TEG module starts operating when the burning process starts. All related sensors are an inactive state in order to record the related information. The stored data in the cloud can be retrieved at any time.

The resulting electrical energy will be stored in a battery and will continuously recharge the battery whenever the energy is produced from the TEG. Figure 2(b) and (c) shows DC and AC power will be created that is equivalent which can be utilized for higher and lower voltage appliances and different information gathered to improve the current efficiency and to know how to control the burning techniques and ways of producing the current in steady as just by using burning process by creating the monitoring system using API or GUI platform. After receiving information from sensors, Arduino will interpret the information and converts it to understandable parameters [20]. All the data which was interpreted by Arduino will be transmitted to cloud using ESP 8266 wifi module via PC-based GUI and Android interface [21].

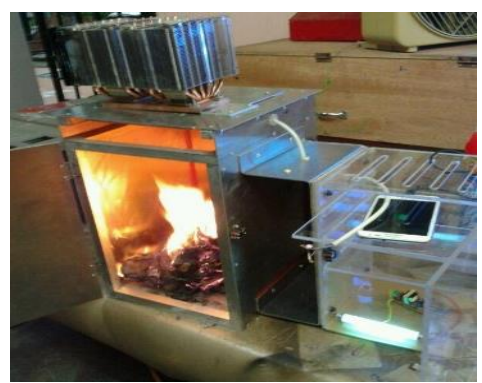

(a)

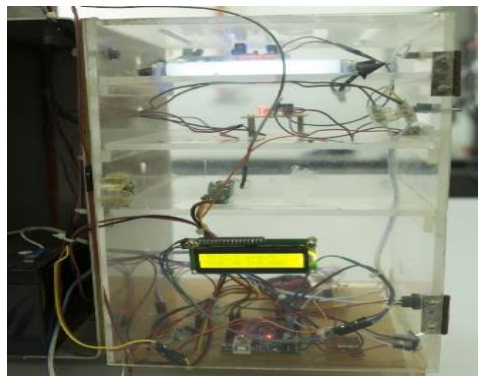

(c)

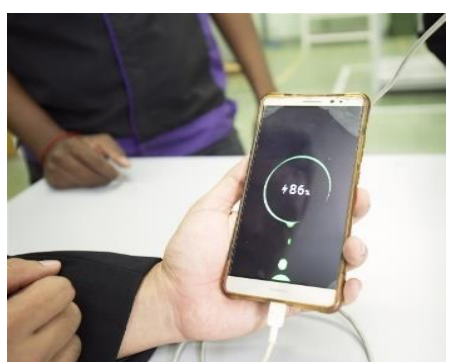

(b)

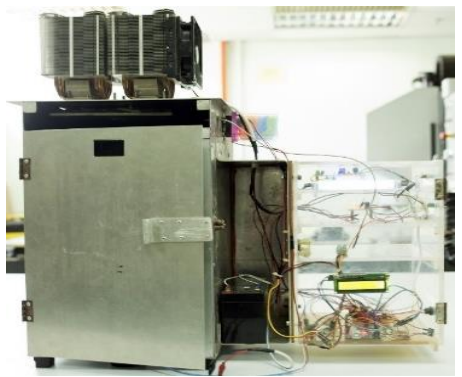

(d)

Figure 2. Hardware implementation. (a) Hardware testing by using the TEG module, (b) DC power source, (c) AC power source, (d) Hardware overall view

\subsection{Software Implementation}

The fundamental stage associated with building this project are; TEG module that is used to convert the heat energy into electrical energy, Arduino Uno microcontroller, sensors: voltage, current, temperature, load, smoke, and humidity, lastly a platform to store every one of the information through cloud IoT [22]. Arduino IDE programming is utilized as a part of request to program ESP $8266 \mathrm{Wi}$-Fi module and Arduino circuit. Google service is used to store all the data starts from the voltage, temperature, humidity, AC and DC voltage that will be generated through the different type of interfaces and stored via a cloud platform. Finally, all these interfaces are developed to monitor the data based on real-time data collected whereby graphs can be produced by selecting different variables such as voltage, current, temperature, weight, and smoke.

\section{ANALYSIS AND DISCUSSION}

There are 5 types of variables taken into consideration which are voltage, current, temperature, weight and smoke observed. These are recorded and analyzed based on different types of material burned such as leaves, twigs, wood, paper, and charcoal. 


\subsection{Method of Analysis}

The method used in order to perform the analysis for the data collected is descriptive and linear regression analysis. Descriptive analysis is brief enlightening coefficients that sum a given informational data, which can be either a portrayal of the whole populace or an example of it. Descriptive statistics are separated into measures of focal propensity and measures of a variable, or spread. Basically, this method is the best prediction at utilizing an arrangement of information to make some sort of data forecast. For this system, based on the collected data and by selecting different variables such as voltage, current, temperature, weight, and smoke; a linear regression graph is produced.

\subsection{Descriptive Analysis}

The obtained results are based on the real-time data of the burning process monitored by Blynk as shown in Figure 3(a). The data can also be monitored using MIT Android app as shown in Figure 3(b). The graphical user interface (GUI) as in Figure 3(c) plays a vital role here where all the monitored data are stored in Google service and can be retrieved any time from the cloud for analytical purposes.

In Figure 4, a voltage versus time graph was produced. Based on the raw data collected from Blynk cloud it can be analyzed that each material produces different voltages in a short span time of 1 minute. In Figure 4 and Figure 5, it can be observed that charcoal produces the highest voltage and power when burned. The amount of energy harvested is the highest compared to other materials. The output power generated which was calculated by using the formula $\mathrm{P}=\mathrm{V}$ x I also supports this. Theoretically, this can be explained by Ohm's law that states that when voltage increases, current also increase as current (I) is directly proportional to voltage (V). As voltage and current increase, power also shows a drastic increase. Wood ranks second for heat emissivity after charcoal because the fixed carbon produced by wood is lower compared to charcoal. Power increases gradually and the material is able to sustain an acceptable amount of voltage for producing electricity. Leaf emits less power due to its low emissivity value. In order to cope with this matter, leaves have to be burned in a larger scale so that more voltage is produced.

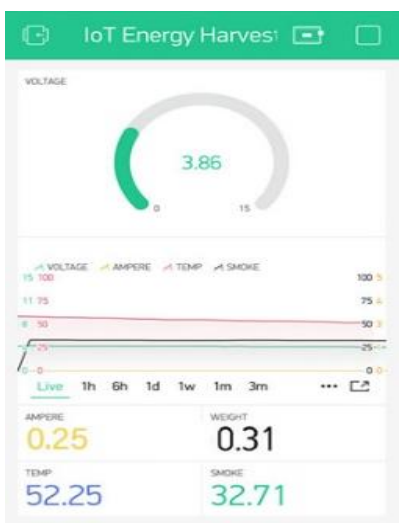

(a)

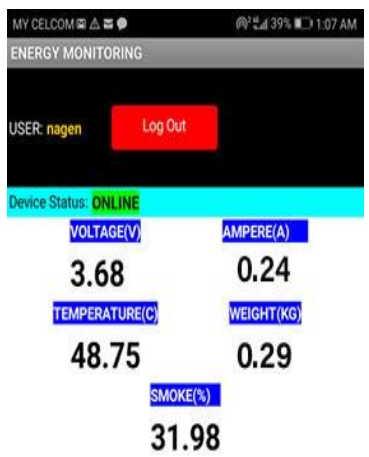

(b)

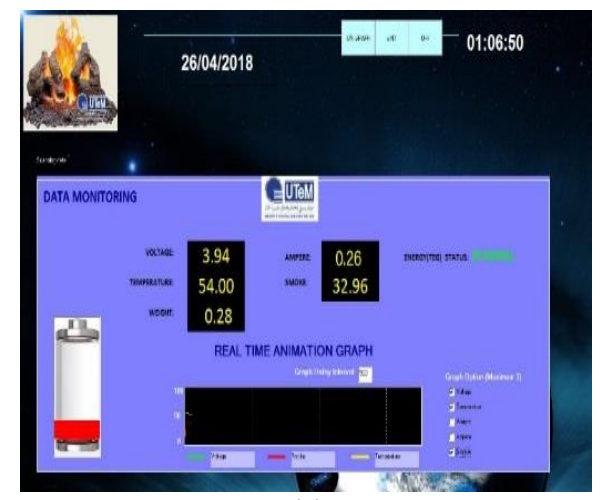

(c)

Figure 3. Type of interfaces. (a) Blynk, (b) MIT App Inventor, (c) Graphical User Interface (GUI)

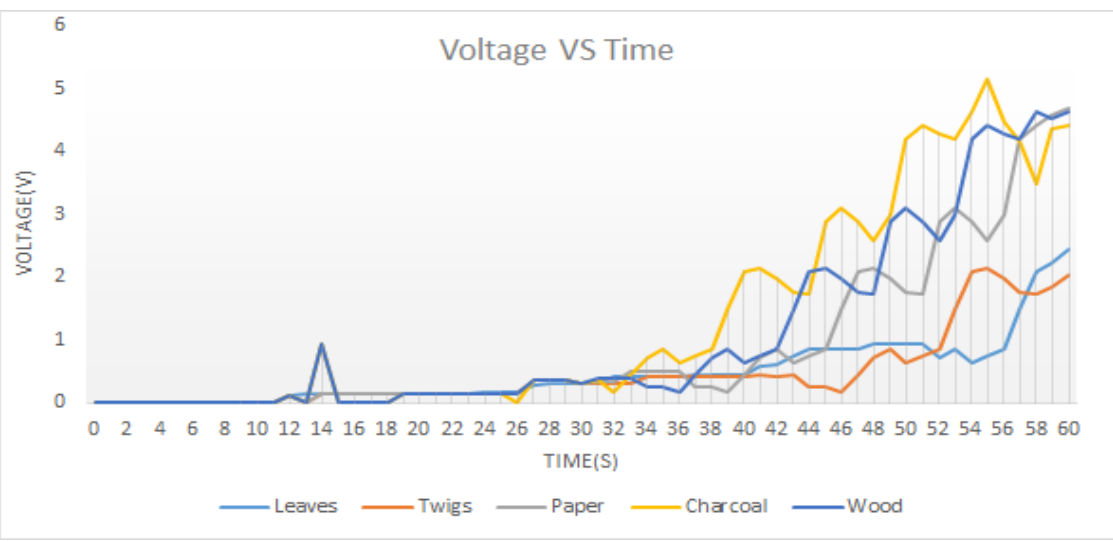

Figure 4. Voltage versus Time graph for five different materials 


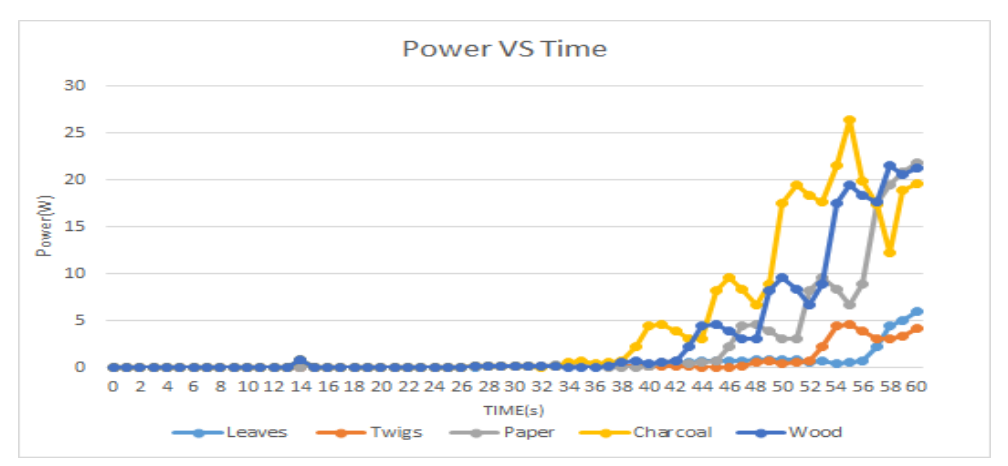

Figure 5. Power obtained versus Time graph for five different materials

\subsection{Linear Regression Analysis}

After analyzing different type of materials, a conclusion was made where charcoal was determined as the best material for power emission. In order to prove this statement, a linear regression analysis was conducted and a linear regression line was produced as shown in Figure 6. Based on the analysis conducted multiple $r$ value obtained was 0.894223 , which means that the value recorded is near to 1 . Theoretically, if the $r$ value always lies between -1 and +1 means there is a correlation between the two variables [23-25]. Hence, this is called a strong positive linear correlation. This is because in terms of producing higher power more weight of the material needs to be burned. Thus, increasing the weight of the material will result in an increase in power generated.

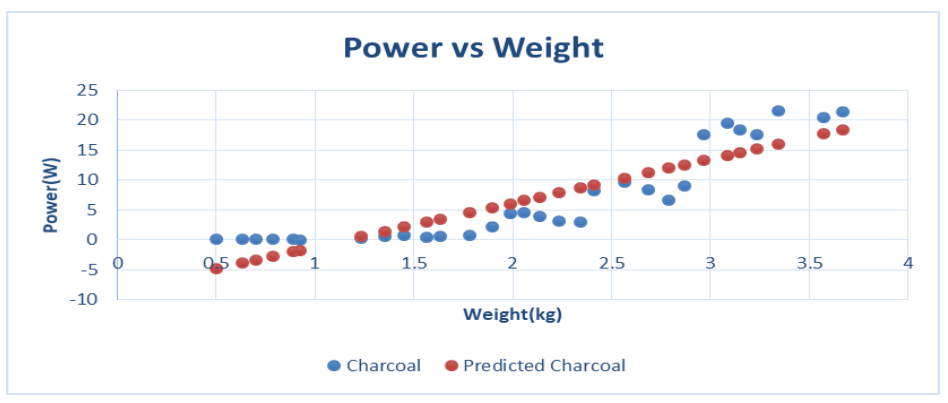

Figure 6. Best line fit graph based on the charcoal regression

\subsection{Mathematical Equation}

The linear regression line has an equation in the form of where $\mathrm{x}$ is an explanatory variable and is the dependent variable. The line slope is $\mathrm{b}$, and $\mathrm{a}$ is the interception (the value of $\mathrm{y}$ when $\mathrm{x}=0$ ) [26]. Based on the data analyzed for charcoal the equation below was produced:

$$
\hat{y}=-8.51561+7.343922 x
$$

This mathematical equation is valuable when making future forecast or signs of past conduct.

\section{CONCLUSION}

People need electricity more importantly during disaster or power outages. This system promises a lot, not only providing electricity during the disaster but this invention can also charge electronic gadgets during outdoor activities such as camping or other activities that makes the traditional electricity inaccessible. The current practice of carrying gas fuel during camping to power up generator can cause major problems where it can spill and increase fire hazard. Moreover, fuel can be pretty expensive in the long run. By using this system, as long as there is a biomass supply of leaves, twigs, wood, paper or charcoal around, it can provide the power source for phones, radio, and light.

This system can also store power inside a rechargeable battery so users can fully charge it prior to leaving for trips and it can aid communication during a disaster or other emergencies. Additionally, this system demonstrates a new method of low-cost energy harvesting compared to solar panels or water turbines. 
In a nutshell, continued research is being conducted to improve this system to reduce the size and also to reduce the smoke emission by adding filters in order to enable cleaner air emission from the system. In addition to that, continued research is being done in terms of analyzing the data collected in order to enhance the quality of the product so that this product can be commercialized.

\section{ACKNOWLEDGEMENTS}

The authors would like to thank Universiti Teknikal Malaysia Melaka (UTeM) for providing the financial support needed to complete the work herein via grant number: PJP/2018/FTK(15A)/S01641

\section{REFERENCES}

[1] R. Domínguez, A. J. Conejo, and M. Carrión, "Toward fully renewable electric energy systems," IEEE Trans. Power Syst., vol. 30, no. 1, pp. 316-326, 2015.

[2] R. Sioshansi and P. Denholm, "05484626.Pdf,” vol. 1, no. 3, pp. 173-183, 2010.

[3] Y. Tu, C. Zhang, J. Hu, S. Wang, W. Sun, and H. Li, "Research on lightning overvoltages of solar arrays in a rooftop photovoltaic power system," Electr. Power Syst. Res., vol. 94, pp. 10-15, 2013.

[4] G. Wang, S. Member, M. Ciobotaru, V. G. Agelidis, and S. Member, "Power Smoothing of Large Solar PV Plant Using," Ieee, vol. 9, pp. 1-9, 2014.

[5] E. A. Bakirtzis, C. K. Simoglou, P. N. Biskas, D. P. Labridis, and A. G. Bakirtzis, "Comparison of advanced power system operations models for large-scale renewable integration," Electr. Power Syst. Res., vol. 128, pp. 90-99, 2015.

[6] S. Ge et al., "Thermoelectric Performance of," vol. 59, no. 12, pp. 3193-3198, 2012.

[7] Z. Tian, S. Lee, and G. Chen, "Heat Transfer in Thermoelectric Materials and Devices," J. Heat Transfer, vol. 135, no. 6, p. 061605, 2013.

[8] K. Y. Lee, D. Brown, and S. Kumar, "Silicon Nanowire Arrays Based On-Chip Thermoelectric Generators," IEEE Trans. Components, Packag. Manuf. Technol., vol. 5, no. 8, pp. 1100-1107, 2015.

[9] J. A. Olsten and S. Mohagheghi, "A low-power thermoelectric generator for off-grid power in the aftermath of natural disasters,” GHTC 2017 - IEEE Glob. Humanit. Technol. Conf. Proc., vol. 2017-January, pp. 1-6, 2017.

[10] S. Kumari, S. S. Sahu, and B. Gupta, "A low voltage pre start-up circuit for thermal energy harvesting applications," Proc. 2017 Int. Conf. Wirel. Commun. Signal Process. Networking, WiSPNET 2017, vol. 2018-January, no. 1, pp. 1970-1973, 2018.

[11] A. N. Abd Razak, N. Mohd Nor, and T. Ibrahim, "Heat energy harvesting for portable power supply," 2011 5th Int. Power Eng. Optim. Conf. PEOCO 2011 - Progr. Abstr., no. June, pp. 436-439, 2011.

[12] Q. Wan, Y. K. Teh, Y. Gao, and P. K. T. Mok, "Analysis and Design of a Thermoelectric Energy Harvesting System With Reconfigurable Array of Thermoelectric Generators for IoT Applications," IEEE Trans. Circuits Syst. I Regul. Pap., vol. 64, no. 9, pp. 2346-2358, 2017.

[13] Y. Wang, S. Lou, Y. Wu, M. Miao, and S. Wang, "Operation strategy of a hybrid solar and biomass power plant in the electricity markets," Electr. Power Syst. Res., vol. 167, no. October 2018, pp. 183-191, 2019.

[14] K. Kim, H. Cha, and H. G. Kim, "A new single-phase switched-coupled-inductor DC-AC inverter for photovoltaic systems,” IEEE Trans. Power Electron., vol. 32, no. 7, pp. 5016-5022, 2017.

[15] D. Inga Narváez, M. V. G. dos Reis, T. A. dos S. Barros, E. R. Filho, and M. G. Villalva, "Performance comparison of DC and AC controllers for a two-stage power converter in energy storage application," Electr. Power Syst. Res., vol. 164, no. July, pp. 47-60, 2018.

[16] E. Sardini and M. Serpelloni, "Self-powered wireless sensor for air temperature and velocity measurements with energy harvesting capability," IEEE Trans. Instrum. Meas., vol. 60, no. 5, pp. 1838-1844, 2011.

[17] M. R. H. Sarker, H. Karim, R. Martinez, N. Love, and Y. Lin, "A lithium niobate high-temperature sensor for energy system applications," IEEE Sens. J., vol. 16, no. 15, pp. 5883-5888, 2016.

[18] S. Dalola et al., "MEMS thermal flow sensor with smart electronic interface circuit," IEEE Sens. J., vol. 12, no. 12, pp. 3318-3328, 2012.

[19] M. Bond and J. Do Park, "Current-sensorless power estimation and MPPT implementation for thermoelectric generators," IEEE Trans. Ind. Electron., vol. 62, no. 9, pp. 5539-5548, 2015.

[20] Y.-W. Lin, $\quad$ Y.-B. Lin, M.-T. Yang, and J.-H.

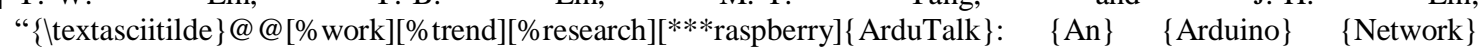
\{Application\} \{Development\} \{Platform\} \{Based\} on \{IoTtalk\}," IEEE Syst. J., pp. 1-9, 2017.

[21] J. Dolinay, P. Dostalek, and V. Vasek, “Arduino Debugger,” IEEE Embed. Syst. Lett., vol. 8, no. 4, pp. 85-88, 2016.

[22] A. Lopez-Vargas, M. Fuentes, and M. Vivar, "IoT Application for Real-Time Monitoring of Solar Home Systems Based on Arduino ${ }^{\mathrm{TM}}$ with 3G Connectivity," IEEE Sens. J., vol. 19, no. 2, pp. 679-691, 2019.

[23] H. Zhu, M. Styner, N. Tang, Z. Liu, W. Lin, and J. H. Gilmore, "FRATS: Functional regression analysis of DTI tract statistics," IEEE Trans. Med. Imaging, vol. 29, no. 4, pp. 1039-1049, 2010.

[24] G. Papageorgiou, P. Bouboulis, and S. Theodoridis, "Robust linear regression analysis-a greedy approach," IEEE Trans. Signal Process., vol. 63, no. 15, pp. 3872-3887, 2015.

[25] H. J. Cho and S. M. Hong, "Median regression tree for analysis of censored survival data," IEEE Trans. Syst. Man, Cybern. Part systems Humans, vol. 38, no. 3, pp. 715-726, 2008.

[26] G. Dong and V. Taslimitehrani, "Pattern-aided regression modeling and prediction model analysis," 2016 IEEE 32nd Int. Conf. Data Eng. ICDE 2016, vol. 27, no. 9, pp. 1508-1509, 2016. 